\title{
STRESS AMONG UNIVERSITY TEACHERS: AN EMPIRICAL RESEARCH IN BULGARIA
}

\author{
P. Valkov ${ }^{1}$, K. Peeva ${ }^{2}$ \\ ${ }^{1}$ Faculty of Education, Trakia University, Stara Zagora, Bulgaria \\ ${ }^{2}$ Faculty of Medicine, Trakia University, Stara Zagora, Bulgaria
}

\begin{abstract}
Purpose: The main purpose of the study was to assess the levels of perceived stress among university teachers and to investigate whether a statistically significant relationship exists between perceived stress scores and age, sex, marital status, workload, financial status, years of teaching and physical activity of university teachers.

Method: The research was carried out at Trakia University, Stara Zagora, Bulgaria. The sample was comprised of 86 university teachers. For statistical processing of the data were used descriptive analysis, Student's T-test and ANOVA with Dunnett's Post Hoc Tests for comparing the means. The IBM Statistical Package for Social Science (SPSS) 25th Version software was used to analyse the data.

Results: There were no significant differences in the level of stress when the respondents were grouped as to age, sex, marital status and workload while a significant difference was found between perceived stress score and financial status, years of teaching, and physical activity.

Conclusion: Stress among university teachers is a serious problem that requires additional research with a larger sample. University teachers should adopt positive coping strategies, such as regular rest and physical activity. Specific recommendations for coping with stress are suggested.
\end{abstract}

Key words: perceived stress score, coping, university teachers, health, physical activity

\section{INTRODUCTION}

Every historical epoch is characterised by certain, clearly distinct physical diseases. Before and shortly after the Second World War diseases that caused most of the deaths were poliomyelitis, tuberculosis, typhoid, encephalitis, etc. Due to vaccines and new medications, they have been brought under control now. As Salk states: ,...we are now leaving an era where the greatest threat to human health was microbial diseases only to enter an era where the greatest threat to humans is stress " (1). It seems that currently every individual has experienced some form of stress. Stress occurs at the individual, organizational and even national level. The topic of stress, in general, and at the workplace in particular, has been the subject of much research in recent years.

*Correspondence to: Petar Valkov, Faculty of Education, Trakia University, 6000 Stara Zagora, Armeyska str. 9, Bulgaria, Tel.: +359 895632139, e-mai: petar.valkov@trakia-uni.bg
Depending on the origin and duration of the impact, stress can be divided into: acute, daily (or chronic) and occupational (2). Chronic stress, without periods of relief, is considered to be more difficult to manage and to have more severe negative consequences than acute stress. In this article, the focus will be on perceived stress among university teachers. The terms academic staff, lecturers, university teachers and academicians are used in this paper interchangeably, and refer to academic staff employed within the university sector.

Teaching at the university is no longer considered as a "stress-free profession". Teaching is considered to be fourth out of ten highly stressful professions in America (3). The work of university teachers is too comprehensive and, in addition to teaching, includes scientific guidance, a publication of articles and books, reports and presentations at scientific conferences, administrative work at the university, conducting and participation in research projects, participation in scientific 
committees, writing reviews of scientific papers, etc. In addition, they have commitments outside the academic environment: family, friends, social, volunteer, etc. According to Watts \& Robertson (4), faculty members experience high levels of stress and burnout similar to those of other demanding service professions (e.g., medical professionals and school teachers). While mild stress can improve working efficiency, excessive chronic stress among university teachers is related to decreased work performance, physiological and mental health problems, and can even lead to burnout, which is defined as a syndrome of exhaustion, cynicism, and reduced professional efficacy $(5,6)$. Furthermore, teachers' stress is also associated with problems of recruitment and retention of teachers, lower job satisfaction and lower quality of education for students $(7,8)$. Long-term exposure to stress may lead to burnout syndrome, which is characterised by emotional exhaustion, depersonalization, and a decrease in personal accomplishment (9). Stress may affect also the way a person cares about himself. In the present study, only $45,3 \%$ of university teachers rate their health as very good or excellent. The most common health problems among university teachers in this study were: gastrointestinal diseases (23,3\%), musculoskeletal disorders $(23,3 \%)$ and cardiovascular diseases, incl. high blood pressure $(19,8 \%)$. Different studies have linked these disorders with occupational stress (10-12). The results show that only $15,1 \%$ of faculty members practice sport regularly (every day or at least three times weekly). They were also aware of not doing enough to take good care of themselves.

\section{FACTORS OF FACULTY STRESS}

Researchers identify several factors associated with high stress among university teachers. These include: excessive workload (13), lack of work-life balance (14), increased number of students to teach (15), lack of university funding, resources and recognition (16) and lack of support from the administration and colleagues (14). To complete the high volume of work, many university staff has to work a high number of unpaid overtime hours, which further contribute to their experience of stress. Other demographic and education-related factors such as sex $(17,18)$, academic position $(19,18)$, age (20) and teaching experience (21) also contribute to experiencing high levels of stress. Full-time educators face higher levels of stress than their part-time colleagues (22). Other sources of stress described in the literature included: decline in staff numbers; an increase in student numbers; the changing nature of students (e.g. "poorer standard" and increased diversity of students); the introduction of new technologies (e.g. webbased and on-line teaching) and unrealistic deadlines (16).

\section{RESEARCH METHODOLOGY}

The main purpose of the study was to assess the level of stress among university teachers. The aim of this study was to investigate whether there exists a statistically significant relationship between perceived stress scores and age, sex, marital status, workload, financial status, years of teaching and physical activity of university teachers. The research was carried out at Trakia University, Stara Zagora, Bulgaria (2018-2019 Academic Year). This university was chosen for this study because it is one of the largest state universities in the country and the results can reflect the nature of stressors in the other state universities in Bulgaria. For statistical processing of the data were used descriptive analysis, Student's T-test and ANOVA with Dunnett's Post Hoc Tests for comparing the means; $\mathrm{P}$ value less than 0,05 was considered statistically significant. The IBM Statistical Package for Social Science (SPSS) $25^{\text {th }}$ Version software was used to analyse the data.

\section{PARTICIPANTS}

The sample is comprised of 86 faculty members of Trakia University. The faculties of the university can be categorized as follows: Faculty of Education ( $\mathrm{N}=31 ; 36,0 \%)$, Faculty of Agriculture $(\mathrm{N}=11 ; 12,8 \%), \quad$ Faculty of Veterinary Medicine $(\mathrm{N}=10 ; 11,6 \%)$, Faculty of Medicine $(\mathrm{N}=9 ; 10,5 \%)$, Faculty of Economics $(\mathrm{N}=8 ; 9,3 \%)$, Faculty Technics and Technology $(\mathrm{N}=12 ; 14,0 \%)$ and Department for Information and In-Service Teachers Training $(\mathrm{N}=5 ; 5,8 \%)$. Participants consisted of 60 females and 26 males and the ages ranged from 27 to 65 (mean age 46,9 years). The majority $(64 \%)$ were married, $14 \%$ were in a live-in relationship and singles were $12,8 \%$ of the sample. The distribution of respondents according to Sex and Age is shown in Table 1.

Table 1. Distribution of Respondents according to sex and age $(N=86)$

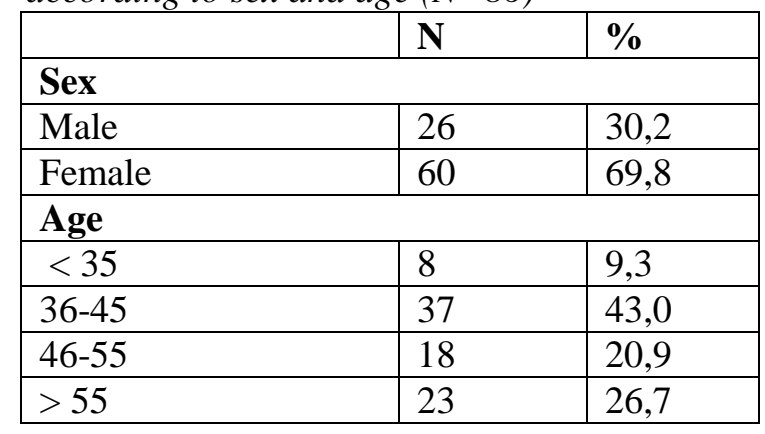




\section{PROCEDURES}

Participants were requested to complete a 20item questionnaire to collect demographic information, including sex, age, marital status, academic rank, workload, teaching experience, birth order, financial status, religion and physical activity. The Perceived Stress Scale (PSS-14), a self-report measure was used to assess "the degree to which situations in one's life is appraised as stressful" (23). PSS items were designed to assess the degree to which respondents perceive their lives as unpredictable, uncontrollable and overloading. These three issues have been repeatedly found to be central components of the stressful experience (ibid).

\section{RESULTS}

In this study $77,9 \%$ of the respondents agree that stress among university teachers in Bulgaria is a serious problem while $15,1 \%$ disagreed with this statement.

The analyses of the data revealed that major stressors were related to the low wages $(65,5 \%)$, lack of recognition for good teaching and research accomplishment (49,4\%), interpersonal conflicts $(48,3 \%)$ and excessive workload $(46 \%)$.

To highlight particular links, perceived stress among university teachers had a significant relationship with teaching experience, financial status and physical activity $(\mathrm{P}<0,05)$. The mean values of perceived stress scores are presented in Table 2 .

No statistically significant differences were found in the levels of perceived stress scores (PSS) and sex $(\mathrm{P}>0,05)$. These findings correspond to some other studies $(24,1)$ where no relationship was found between sex and stress levels. Contrary to these findings, Smith, et al. found that female university teachers experience greater stress than their male colleagues (25). The explanations for these conflicting findings are complex and might be related to the greater workload of at home and care of the children (26).

In this study, $64 \%$ of the respondents were married, $14 \%$ were in unmarried cohabitation, $9,3 \%$ were widows/widowers and $12,8 \%$ were singles. The analysis shows no statistically significant differences between levels of perceived stress scores according to marital status. However, the mean values of perceived stress scores are lower in singles than in university teachers with another marital status (Table 2). The disproportionality in the sample (married to singles ratio is more than 5:1) may have contributed to the lack of statistically significant relationship between these two variables. On the other side, higher perceived stress levels might be related to a family-work imbalance that married university teachers often face and which may increase the stress levels. These findings are not consistent with other studies, where unmarried and divorced participants were found to be more stressed than married persons (27). These authors argue that married persons feel less stressed, which is consistent with evidence that social support may reduce psychological stress. Such support may come not only from the spouse, but also from her/his parents, siblings, relatives and friends, and later in life, the children greatly expanding the possible sources of support in stressful situations.

Although age did not appear to be a significant factor in the relationship with perceived stress $(P>0,05)$, the results show lower levels of stress in people under 35 and over 55 years of age. Teachers aged 46-55 are exposed to the highest level of stress (mean PSS was 26,33). A possible explanation for lower stress in older teachers provides Carstensen (28) and his Socioemotional selectivity theory, according to which younger individuals perceive time as more open-ended, and thus prioritize and pursue knowledge-related goals. In contrast, older individuals perceive time as more limited, and instead prioritize social and emotion-related goals. The theory states, that older adults tend to focus more on the positive and less on negative emotions (e.g. reduced exposure to daily hassles). For example, compared with younger adults, older adults are more likely to forgive others in interpersonal conflicts (29). These strategies enable older adults to focus their limited time and energy on social partners and interactions that are likely to be pleasant, which contributes to their emotional well-being and reduces stress in their life.

With regard to the academic rank, lower stress levels were generally observed among associate professors (mean PSS was 23,48), although no statistically significant relationship was found between academic rank and stress level $(\mathrm{P}>0,05)$. According to some other studies, however, associate professors are more stressed and unhappy than assistant professors or (full) professors $(30,31)$. A possible reason for these conflicting findings could be the differences in contracts for the university employees in each country (e.g. fixed-term vs. indefinite-term employment) and different compulsory teaching hours depending on academic rank. 
Table 2. Demographic characteristics and the mean of perceived stress scores (PSS)

\begin{tabular}{|c|c|c|c|}
\hline Socio-demographic variables & $\mathbf{N}$ & $\%$ & PSS \\
\hline \multicolumn{4}{|l|}{ Sex } \\
\hline Male & 26 & 30,2 & 24,08 \\
\hline Female & 60 & 69,8 & 24,20 \\
\hline \multicolumn{4}{|l|}{ Age } \\
\hline$<35$ years & 8 & 9,3 & 22,88 \\
\hline $36-45$ years & 37 & 43,0 & 24,08 \\
\hline $46-55$ years & 18 & 20,9 & 26,33 \\
\hline$>55$ years & 23 & 26,7 & 23,04 \\
\hline \multicolumn{4}{|l|}{ Marital status } \\
\hline Married & 55 & 64,0 & 24,58 \\
\hline Cohabitating without marriage & 12 & 14,0 & 24,25 \\
\hline Divorced/widowed & 8 & 9,3 & 24,63 \\
\hline Single & 11 & 12,8 & 21,64 \\
\hline \multicolumn{4}{|l|}{ Academic rank } \\
\hline Assistant Professor without doctoral degree & 18 & 20,93 & 24,06 \\
\hline Assistant/Chief Assistant Professor with doctoral degree & 29 & 33,7 & 24,55 \\
\hline Associate Professor & 29 & 33,7 & 23,48 \\
\hline Professor & 10 & 11,6 & 24,90 \\
\hline \multicolumn{4}{|l|}{ Teaching experience (years) } \\
\hline$<9$ years & 28 & 32,5 & 22,75 \\
\hline $10-19$ years & 26 & 30,2 & 26,77 \\
\hline$>20$ years & 32 & 37,2 & 23,28 \\
\hline \multicolumn{4}{|l|}{ Teaching load (for last academic year, in hours) } \\
\hline$<300$ hours & 10 & 11,6 & 25,30 \\
\hline 300-399 hours & 22 & 25,6 & 24,32 \\
\hline 400-499 hours & 19 & 22,1 & 22,32 \\
\hline $500-600$ hours & 17 & 19,8 & 25,71 \\
\hline$>600$ hours & 18 & 20,9 & 23,83 \\
\hline \multicolumn{4}{|l|}{ Financial status } \\
\hline Below the poverty line/Make ends meet & 8 & 9,3 & 28,50 \\
\hline Neither rich, nor poor & 66 & 76,7 & 24,18 \\
\hline Well-off & 12 & 14,0 & 21,17 \\
\hline \multicolumn{4}{|l|}{ Religiosity (religious, believer) } \\
\hline No & 6 & 7,0 & 23,33 \\
\hline Rather no than yes & 13 & 15,1 & 19,85 \\
\hline Hard to answer & 7 & 8,1 & 25,03 \\
\hline Rather yes than no & 33 & 38,4 & 25,15 \\
\hline Yes & 27 & 31,4 & 24,16 \\
\hline \multicolumn{4}{|l|}{ Physical activity } \\
\hline Rarely & 45 & $52,3 \%$ & 25,80 \\
\hline Once a week & 16 & $18,6 \%$ & 20,50 \\
\hline Less than three times weekly & 12 & $14,0 \%$ & 23,00 \\
\hline Three or more times weekly & 10 & $11,6 \%$ & 25,70 \\
\hline Every day & 3 & $3,5 \%$ & 18,67 \\
\hline
\end{tabular}

The results show a statistically significant relationship between the levels of perceived stress and teaching experience $(\mathrm{P}=0,038)$, where teachers having up to 9 years and over 20 years of teaching showed lower levels of stress. Academic staff with teaching experience between 10 and 19 years showed the highest levels of stress (Table 2). This subgroup is most likely comprised by associate professors who strive to become full professors and receive greater status and salary. The higher perceived stress scores among them 
may be explained with the inequitable delegation of responsibilities by the department, the more administrative workload for tenures, a high number of unpaid overtime hours in order to complete the high volume of work needed for the next academic rank, competition and limited opportunities for promotion (Figure 1).

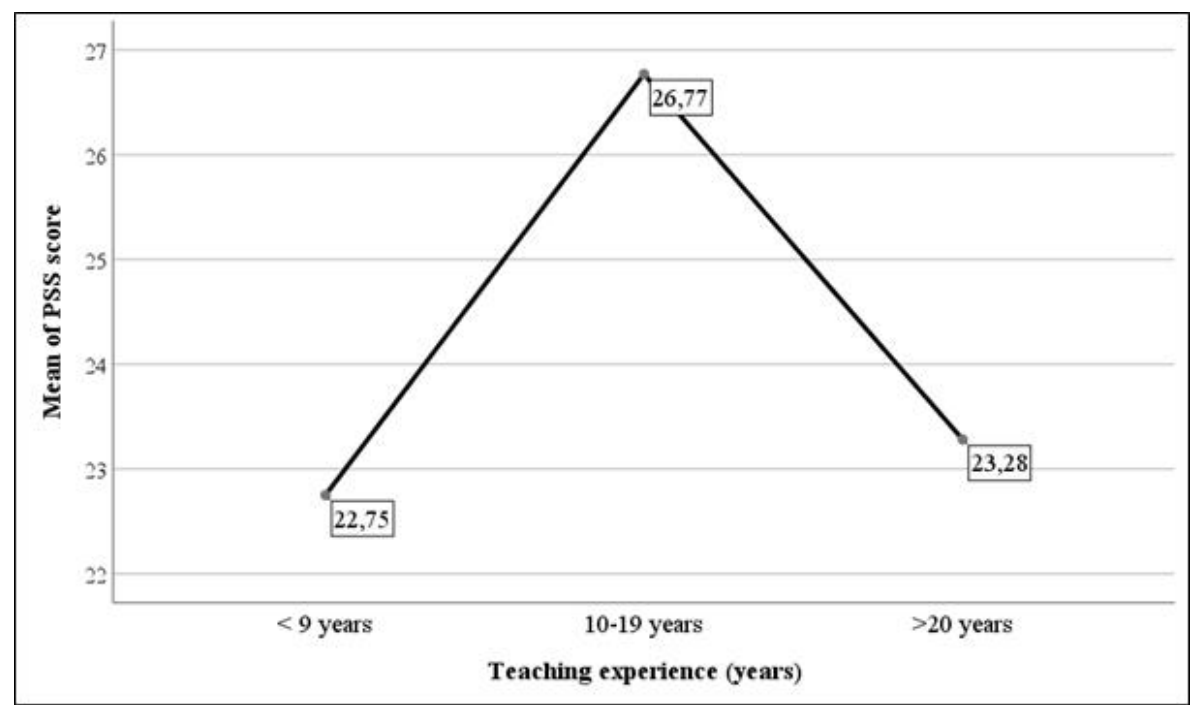

Figure 1. Level of perceived stress scores and the teaching experience.

No statistically significant relationship was obtained between the teaching load (for the last academic year in hours) and perceived stress $(\mathrm{P}>0,05)$. The difference between perceived stress and teaching load turned out to be insignificant, and this may be due to the fact that the work of university professors is too comprehensive and, in addition to teaching includes scientific guidance, publication, reports at scientific conferences, administrative work conducting and participating in research projects, participation in scientific committees and writing reviews. Each of these responsibilities individually or in combination with others may increase the levels of perceived stress among university professors.

Further results indicated differences in perceived stress depending on income. A statistically significant relationship was found between financial status and the level of perceived stress $(\mathrm{P}=0,038)$ (Figure 2). As expected, the subjects living below the poverty line or who find it difficult to make ends meet, have the highest levels of perceived stress (PSS-28,50) while those who are well-off - the lowers (PSS-21,17). Direct evidence that lower income is related to higher perceived stress levels was provided by Klein et. al. (27).

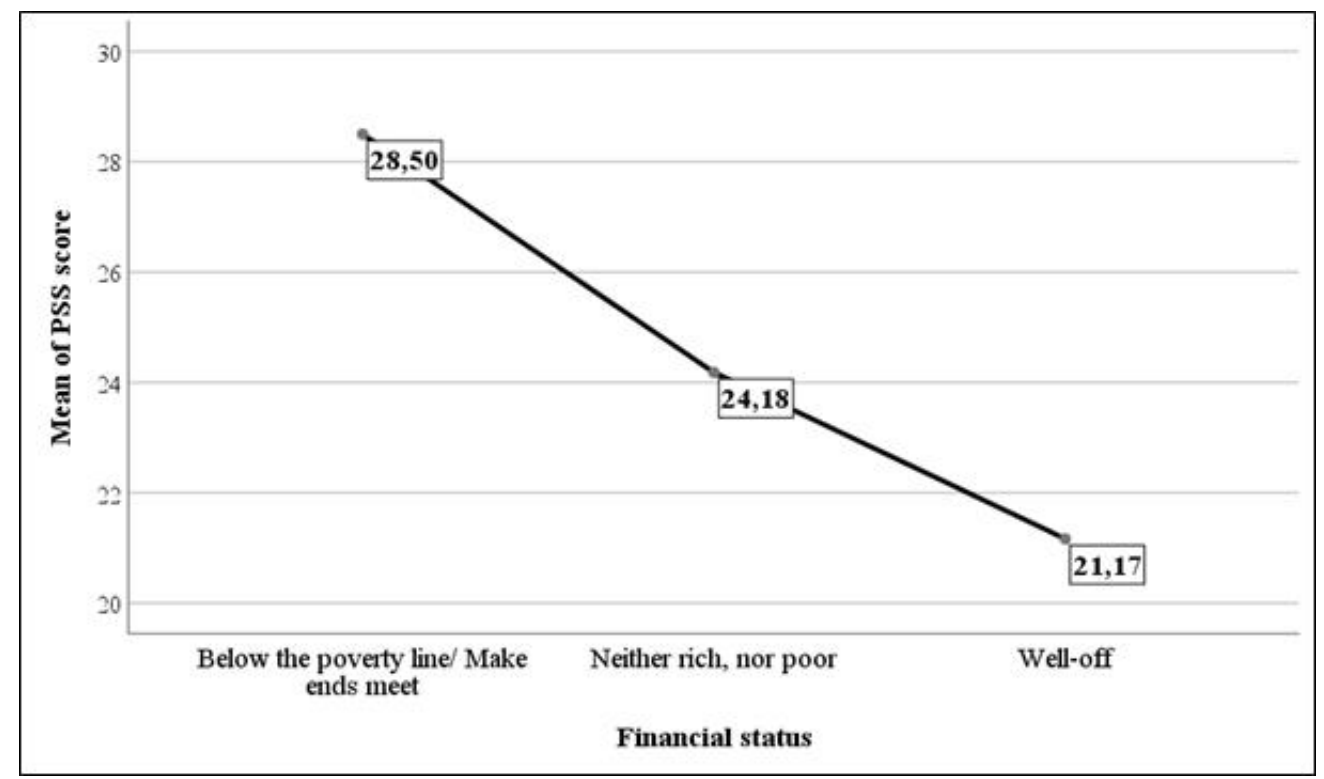

Figure 2. Level of perceived stress scores and the financial status. 
According to the same study, men with lower income reported more stress than women in the same income level, whereas men earning more money felt less stressed than women with comparably high income (Figure 3). These findings suggest that the relationship between income and perceived stress is stronger in men than in women.

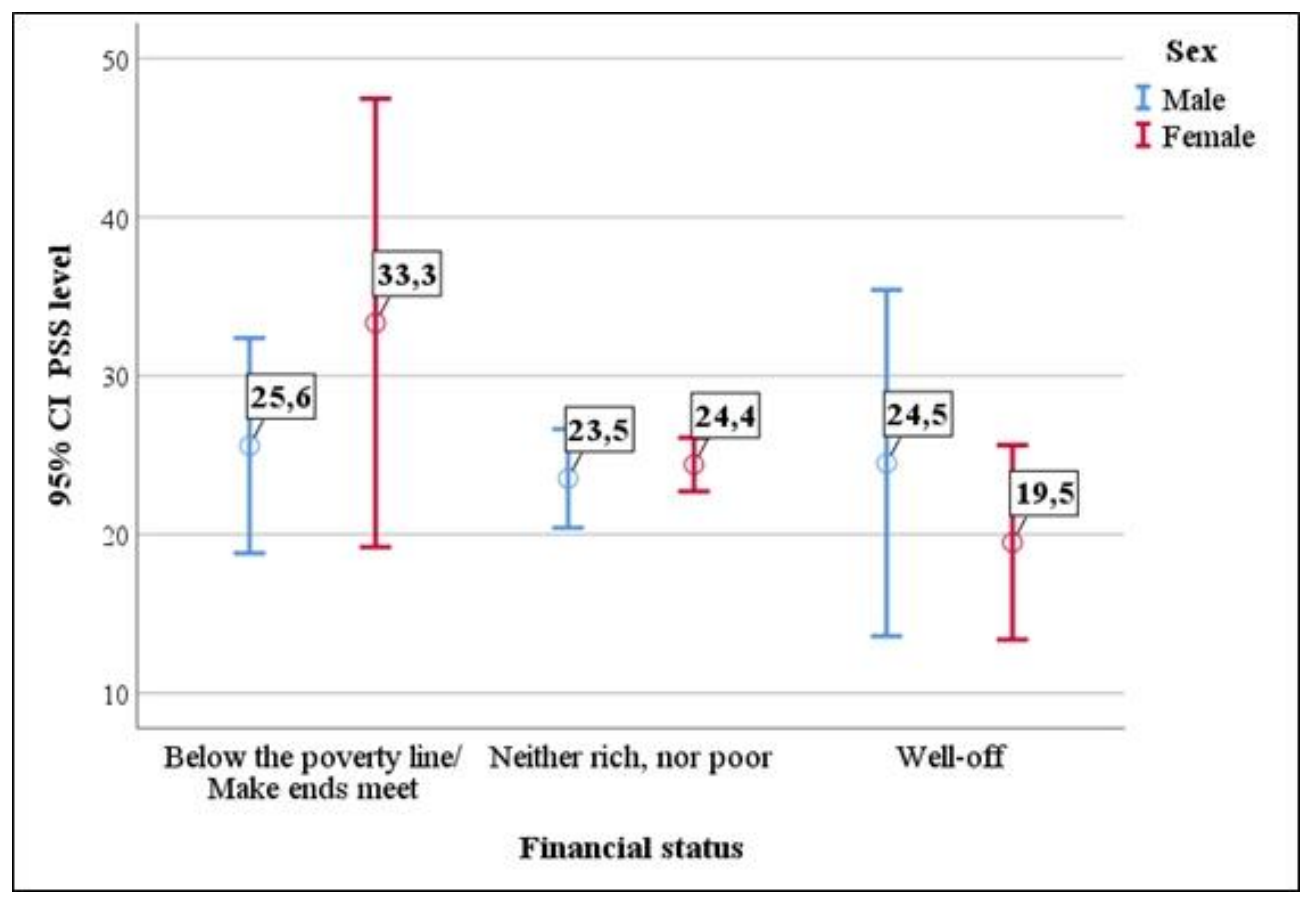

Figure 3. Level of perceived stress scores by gender according to financial status.

Interestingly, religion did not show a significant effect on perceived stress, although is considered by some researchers as a coping strategy (32) and religious coping has been a research topic in the investigation of psychological adjustment to stress (27). The belief that God is enabling the individual to bear their troubles (religious/spiritual support), belief that it was all for the best, and belief that all is ultimately controlled by God may have comforting effects in time of stress. However, such religion-related cognitions might directly impact positive affect, but not distress (33).

The results demonstrated a negative relationship between perceived stress and the frequency of physical activity $(\mathrm{P}=0,017)$. As expected, perceived stress correlated negatively with sport- University teachers, who are physically active every day showed the lowest scores on the PSS-14 and those, who participate in physical activity rarely - the highest (Figure 4). Interestingly, university teachers who are physically active three or more times a week have nearly the same perceived stress levels as those who are rarely physically active. These findings suggested, that physical activity is surely not the only factor influencing perceived stress levels. Overall, the university teachers in the present research showed a lower frequency of physical activity (52,3\% - rarely; $18,6 \%$ - once a week). This insufficient physical activity might be related to the other findings of this study, where every fifth teacher suffers from cardiovascular disease, incl. high blood pressure $(19,8 \%)$, almost as much - from obesity $(18,6 \%)$ and from gastrointestinal diseases $(23,3 \%)$.

Different studies have linked all these disorders with the occupational stress (10-12, 16). As the results of this and many other studies show, regular physical activity could significantly reduce stress, which in turn decreases the risk for these diseases. The health benefits of physical activity for adults have been well established in the literature, such as the reduced prevalence of common chronic conditions (e.g. cardiovascular disease, diabetes, hypertension), improved mental health (e.g. depression, anxiety), quality of life, increased physical function, decreased cognitive decline (e.g. dementia, Alzheimer's disease), and reduced mortality rates $(34,35)$. 


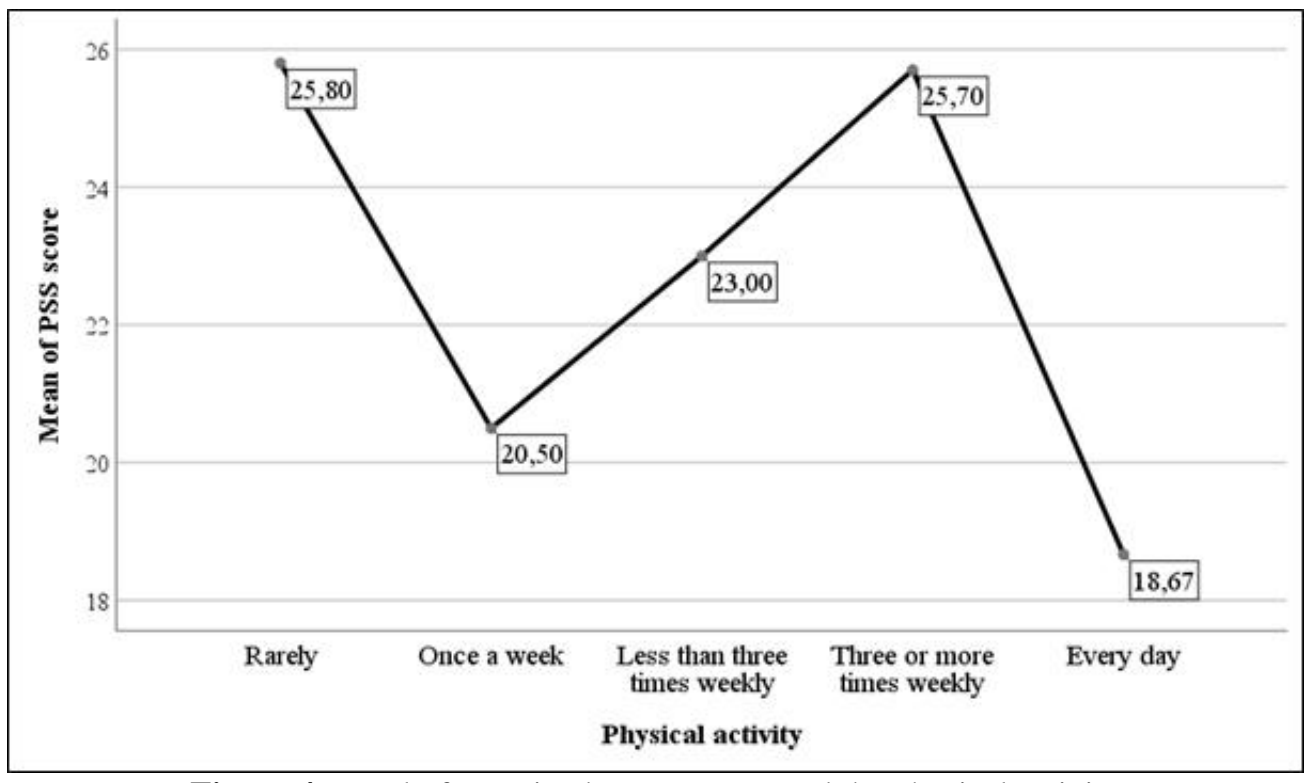

Figure 4. Level of perceived stress scores and the physical activity

\section{DISCUSSION AND RECOMMENDATIONS}

The findings of the present study show that perceived stress among university teachers had significant relationship with teaching experience, financial status and physical activity. Lecturers with teaching experience between 10 and 19 years showed the highest levels of stress. As expected, the subjects living below the poverty line or who find it difficult to make ends meet, have the highest levels of perceived stress scores, while those who are well-off have the lowest.

The results indicated a negative relationship between perceived stress and physical activity. Those university teachers, who are physically active every day showed significantly lower perceived stress scores. Physical activity and sport are important primary stress prevention with numerous health benefits. However, as the findings of the present research show, physical inactivity is a serious problem for the faculty staff at Trakia University, where $70 \%$ of university teachers are insufficiently physically active.

The current higher education system is associated with increased stress for university teachers in Bulgaria through the low wages, insufficient research funding, lack of recognition for good teaching and research accomplishment and excessive workload. Therefore, decreasing the workload and enhancing opportunities for occupational rewards (income, recognition and career opportunities) could be used to reduce stress among university teachers.

Finally, a few limitations need to be considered. Data are limited to self-report which can lead to response bias, the sample size was small. Although significant differences were found, the effect of the measured characteristics on stress levels is to be interpreted with caution. This study has sampled only a single university and has focused only on the stress experienced by academics, with no exploration of stress on general university staff. Because of the crosssectional study design the results do not allow drawing any causal conclusion and future longitudinal studies are needed to better analyse the relationship between variables and perceived stress.

\section{CONCLUSION}

Despite the limitations listed above, the results of this study showed that stress among university teachers is a serious problem that requires additional research with a larger sample and specific measures to cope with workplace stress. Teaching at the university is no longer considered as a "stress-free profession "and is considered to be 4th out of 10 highly stressful professions in America (3). It is well documented, high levels of occupational stress, if left unchecked and unmanaged, is associated with faster physical and emotional depletion and increased cynicism and negativity towards others (depersonalization, dehumanization), low job 
satisfaction and low job commitment, decreased productivity, increased anxiety and depression (16). Various factors may contribute to the high level of stress in teachers. As expected, the most common stressors among university lecturers are low wages/income and lack of recognition for good teaching and research. However, the current study also identified interpersonal conflicts as a major source of stress that has "displaced" excessive workload as the third leading cause of stress at the workplace. University teachers should adopt positive coping strategies to relax, such as having daily rest (enough sleep), weekly rest (on the weekends) and annual rest (holiday for at least two weeks at a time) and participate in regular physical exercise. Additionally, psychological counselling and stress management courses should be provided to teachers to improve their stress-coping skills. Unfortunately, in Bulgaria, the costs of psychotherapy are not covered yet by the National Health Insurance Fund. Depression and anxiety disorders (caused often by stress) are treated mainly with medications and symptomatic, treating the symptoms and not the underlying cause. As Breggin states, "psychiatric drugs frequently cloud the mind, impair judgement and insight, suppress emotions and spirituality, inhibit relationships and love, and reduce will power and autonomy" (36). He argues, that instead of suppressing the painful emotions with psychoactive drugs, including psychiatric medications, people can liberate themselves from guilt, shame, and anxiety (emotions related to stress) learning to require mutually respectful relationships in which love can thrive. Leaving the negative emotions behind, people become more able to love, which, in turn, reduces stress and leads to a much easier and richer life.

\section{REFERENCES}

1. Atindanbila, S. Perceived Stressors of Lecturers at the University of Ghana, Journal of Emerging Trends in Educational Research and Policy Studies, 2 (5): 347354, 2011.

2. Nikolkova S., Marinov, P. (Eds.), Psychiatry, psychology and psychotherapy. - For general practitioners, Sofia: University Publishing Medicine, 168, 2007.

3. Yasin, S., Naqvi, S. Gender and institutional differences in job satisfaction, professional stress \& work family conflict in academia. Pakistan Journal of Psychology. Vol. 47 Issue 1, 71-84, 2017

4. Watts, J., Robertson, N. Burnout in university teaching staff: a systematic literature review, Educational Research, Vol. 53, Issue 1, p. 33-50, 2011.

5. Steinhardt M., Jaggars S., Faulk K., et al. Chronic work stress and depressive symptoms: assessing the mediating role of teacher Burnout. Stress Health. Dec. 27 (5):420-429. PubMed PMID: WOS: 000298298900009, 2011.

6. Burke R., Greenglass E., Schwarzer R. Predicting teacher burnout over time: effects of work stress, social support, and self-doubts on burnout and its consequences. Anxiety, Stress \& Coping: An International Journal, 9 (3): 261-275. PubMed PMID: WOS:A1996VG64900007, 1996.

7. You S., Conley S. Workplace predictors of secondary school teachers' intention to leave: an exploration of career stages. Educ. Manag. Adm. Lead. Jul;43 (4):561-581. PubMed PMID: WOS:000360483100006, 2015.

8. Makela K., Hirvensalo M., Whipp P. Determinants of PE teachers career intentions. J. Teach Phys Educ. Oct;34(4):680-699. PubMed PMID: WOS:000365554100009, 2015.

9. Maslach, C., Jackson, S. E., Leiter, M. P. Maslach Burnout Inventory (3rd ed.). Palo Alto, CA: Consulting Psychologists Press, 1996.

10.Backé E., Seidler A., Latza U., Rossnagel K, Schumann B. The role of psychosocial stress at work for the development of cardiovascular diseases: a systematic review. Int Arch Occup Environ Health; 85:67-79, 2012.

11.Papaefthymiou A., Doulberis M., Kountouras J., et. al. Impact of occupational stress on irritable bowel syndrome pathophysiology and potential management in active duty noncombat Greek military personnel: a multicenter prospective survey. European Journal of Gastroenterology \& Hepatology, Vol 31-8, p. 954-963, DOI: 10.1097/MEG.0000000000001439, 2019.

12. Mariammal T, Jaisheeba AA, Sornaraj R. Work influenced occupational stress and cardiovascular risk among teachers and office workers. Chem Pharm Res. 4 (3), p. 1807-11, 2012. 
13.Abbas, S. G., \& Roger, A. The impact of work overload and coping mechanisms on different dimensions of stress among university teachers. @GRH 2013/3 (8), 93118. https://doi.org/10.3917/grh.133.0093, 2013.

14.Slišković, A., Maslić Seršić, D. Work stress among university teachers: Gender and position differences. Archives of Industrial Hygiene and Toxicology, 62, 299-307. https://doi.org/10.2478/10004-1254-622011-2135, 2011.

15.Jamison, M., \& Enrera, J. Factors affecting work productivity among the female faculty of allied medical health colleges of University of Hail, Saudi Arabia. IOSR Journal of Nursing and Health Science, 4 (6), 25-39, 2015.

16.Gillespie, N., Walsh, M., Winefield, A., Dua, J., \& Stough, C. Occupational stress in universities: Staff perceptions of the causes, consequences and moderators of stress. Work and Stress, 15, 53-72. Retrieved from:

https://www.tandfonline.com/doi/abs/10.10 80/02678370117944, 2001.

17.Hart, J., \& Cress, C. Are women faculty just "worrywarts?" Accounting for gender differences in self-reported stress. In D. R. Buckholdt, \& G. E. Miller (Eds.), Faculty stress (pp. 174-192). New York, NY: Routledge, 2009.

18.Donovan, R. A. Perceptions of stress, workload, and job satisfaction among HSS faculty: Executive summary. Retrieved from

http://dean.hss.kennesaw.edu/docs/tea-

terrace_donovan-06-12_exec-summary.pdf , 2012.

19. Colacion-Quiros, H., Gemora, R. Causes and effects of stress among faculty members in a state university. Asia Pacific Journal of Multidisciplinary Research, 4 (1), 18-27. Retrieved from: http://www.apjmr.com/wpcontent/uploads/2016/03/APJMR2016.4.1.04.pdf, 2016.

20.Lindholm, J. A., \& Szelényi, K. Faculty time stress: Correlates within and across academic disciplines. In D. R. Buckholdt, \& G. E. Miller (Eds.), Faculty stress (pp. 19-40). New York, NY: Routledge, 2009.

21.Schuldt, B., Totten, J. An exploratory study: Business faculty and the Faculty Stress Index. Proceedings of the Allied Academies, 15(2), 128-133, 2008.
22.Tan, J. Factors Affecting Stress among Faculty Members of Public Universities in the Philippines: A Multiple Regression Analysis, International Journal of Psychological Studies; Vol. 9, No. 3; ISSN 1918-7211 E-ISSN 1918-722X, Published by Canadian Center of Science and Education, 2017.

23. Cohen, S., Kamarck T. \& Mermelstein, R. A global measure of perceived stress. Journal of Health and Social Behaviour, 24, 385-396, 1983.

24.Winefield, A.H., Jarrett, R. Occupational Stress in University Staff. International Journal of Stress Management 8, 285-298 https://doi.org/10.1023/A:1017513615819, 2001.

25.Smith, E., Anderson, J. \& Lovrich, N.P. Research in Higher Education 36: 261. https://doi.org/10.1007/BF02208311, 1995.

26.Elliott, M. Gender differences in the causes of work and family strain among academic faculty. Journal of Human Behavior in the Social Environment, 17 (1-2), 157-173, 2008.

27.Klein, E., Brähler, E., Dreier, M., Reinecke, L., Müller, K., Schmutzer, G., Wölfling, K., $\&$ Beutel, M. The German version of the Perceived Stress Scale - psychometric characteristics in a representative German community sample. BMC psychiatry, 16, 159. https://doi.org/10.1186/s12888-0160875-9, 2016.

28.Carstensen L., Isaacowitz D., Charles S. Taking time seriously: a theory of socioemotional selectivity. Am. Psychol. 54 (3):165. 1999.

29.Allemand, M. Age differences in forgiveness: The role of future time perspective. Journal of Research in Personality, 42, 1137-1147, 2008.

30.Jong, L. Why are associate professors so unhappy? The Chronicle of Higher Education, 2012.

31.Kroll, D. Top 10 reasons being a university professor is a stressful job. Forbes, retrieved from: https://www.forbes.com/sites/davidkroll/20 13/01/05/top-10-reasons-being-auniversity-professor-is-a-stressfuljob/\#7069cdaa71c1, last visited on 27.06.2019, 2013.

32.Pargament, K., Park, C. In times of stress: The religion-coping connection. In B. Spilka \& D. N. McIntosh (Eds.), The psychology of religion: Theoretical 
approaches (p. 43-53). Westview Press, 1997.

33.Loewenthal, K., MacLeod, A., Goldblatt, V., Lubitsh, G., Valentine, J. Comfort and joy? Religion, cognition, and mood in Protestants and Jews under stress, Cognition and Emotion, 14:3, 355-374, DOI: 10.1080/026999300378879, 2000.

34.Musich, S., Wang, S., Hawkins, K., Greame C. The Frequency and Health Benefits of Physical Activity for Older Adults, Population Health Management. Jun.199207. http://doi.org/10.1089/pop.2016.0071, 2017.
35.World Health Organization. Global recommendations on physical activity for health. ISBN: 9789241599979, 2010.

36.Breggin, P. Understanding and Overcoming Guilt, Shame, and Anxiety: Based on the Theory of Negative Legacy Emotions, In: Promoting Psychological Wellbeing in Children and Families, Palgrave Macmillan UK, doi: 10.1057/9781137479969, 2015. 